\title{
Leisure-Time Sedentary Behavior Is Associated with Psychological Distress and Substance Use among School-Going Adolescents in Five Southeast Asian Countries: A Cross-Sectional Study
}

\author{
Supa Pengpid ${ }^{1,2}$ and Karl Peltzer ${ }^{2, *}$ \\ 1 ASEAN Institute for Health Development, Mahidol University, Salaya, Nakhon Pathom 73170, Thailand; \\ supaprom@yahoo.com \\ 2 Deputy Vice Chancellor Research and Innovation Office, North West University, \\ Potchefstroom 2531, South Africa \\ * Correspondence: karl.peltzer@tdtu.edu.vn
}

Received: 23 April 2019; Accepted: 10 June 2019; Published: 13 June 2019

\begin{abstract}
Sedentary behavior has been found to be associated with poorer mental health. The aim of this study was to estimate associations of sedentary behavior with psychological distress and substance use among adolescents in five Southeast Asian countries. The cross-sectional sample included 32,696 nationally representative samples of school-going adolescents (median age 14 years) from Indonesia, Laos, Philippines, Thailand and Timor-Leste. Leisure-time sedentary behavior, physical activity, psychological distress and substance use were assessed by self-report. Overall, the students engaged in $<1 \mathrm{~h}(35.7 \%), 1-2 \mathrm{~h}(31.6 \%), 3-4 \mathrm{~h}(18.2 \%), 5-6 \mathrm{~h}(7.2 \%)$, and 7 or more hours $(7.2 \%)$ of sedentary time a day. The prevalence of psychological distress was $14.6 \%$ single and $8.6 \%$ multiple psychological distress, and the prevalence of current tobacco use was $13.9 \%$ and current alcohol use $12.5 \%$. In fully adjusted multinomial logistic regression analysis, compared to students who spent less than one hour a day engaged in sedentary leisure time, students who spent three or more hours engaged in leisure-time sedentary behavior were more likely to have single and multiple psychological distress. In fully adjusted logistic regression analysis, five or more hours of leisure-time sedentary behavior was associated with current tobacco use and one or more hours of leisure-time sedentary behavior with current alcohol use. Findings suggest an association of leisure-time sedentary behavior with psychological distress and with substance use in this adolescent population.
\end{abstract}

Keywords: sedentary behavior; physical activity; psychological distress; tobacco use; alcohol use; adolescents

\section{Introduction}

During the adolescence period, a significant risk exists for the development of mental and substance use disorders [1], and health risk behaviors are formed which have long lasting effects on health [2,3]. Sedentary behavior ("referring to certain activities in a reclining, seated, or lying position requiring very low energy expenditure" [4]) is one of the health risk behaviors, which may have been significantly increasing in the lives of adolescents [5], and has been implicated with greater risk of obesity, non-communicable diseases and mortality $[5,6]$. Sedentary behavior may have been increasing because of a change from physically demanding tasks to more knowledge-based activities [7]. This may be reflected by activities such as social media use or computer "chatting", being associated with poorer mental health, such as depression $[7,8]$. 
Growing evidence seems to show links between sedentary behavior and poor mental health among adolescents [2,9-12]. In a systematic review among adolescents, Hoare et al. [2] found a strong relationship between leisure screen time and both depressive symptoms and psychological distress; poorer mental health status was found in those with 2-3 h or more per day of screen time [2]. In a more recent review, Rodriguez-Ayllon et al. [13] found that greater amounts of sedentary behavior was associated with poorer mental health (depression) but associations with psychological distress were unclear. Using data from the multi-country "Global School-Based Student Health Survey (GSHS)", Vancamfort et al. [9-12] found that leisure-time sedentary behavior was associated with various poor mental health indicators (depressive symptoms, loneliness, suicide attempt and anxiety-induced sleep disturbance).

Less evidence was found for an association between sedentary behavior and substance use among adolescents [14-16]. Among school-going adolescents in Slovenia, computer use time ( $\geq 2 \mathrm{~h} /$ day) was associated with tobacco and alcohol use [14], among Hispanic adolescents, sedentary behavior was associated with alcohol use [15], and in a study among in-school adolescents in eight African countries, leisure-time sedentary behavior (3-4 h or more/day) was associated with tobacco, alcohol and drug use [16]. We are not aware of studies investigating the relationship between sedentary behavior and psychological distress and substance use among adolescents in Asia.

More research is needed to study the independent associations of sedentary behavior with psychological distress and substance use among adolescents, in particular in Southeast Asia. In a study among adolescents in seven Southeast Asian countries, an association between loneliness, current alcohol use and sedentary behavior was found [17]. Possible mechanisms for negative effects of sedentary behavior on mental health are not clear [13]. "It is possible that the beneficial pathophysiological, social and general health benefits of being active may be omitted when sedentary, which may have a negative impact on mental health. Adolescents who experience poorer mental health may lack of motivation to be physically active and may turn to screen based activities requiring little effort as a coping mechanism, and therefore lose such protective effects of physical activity." [2]. It was hypothesized that higher leisure-time sedentary behavior will be associated with a higher prevalence of psychological distress and substance use.

This study aimed to investigate the associations of leisure-time sedentary behavior with psychological distress and with substance use among school-going adolescents in five Southeast Asian countries.

\section{Materials and Methods}

\subsection{Sample and Procedure}

Cross-sectional data from the GSHS of five Southeast Asian countries (which had collected data as recent as 2015) were analyzed. The GSHS uses a "cluster sampling design in two stages (schools and classrooms) in order to produce nationally representative samples of school children in middle schools" [18]. "Students completed a self-administered questionnaire under the supervision of trained survey administrators" [18]. Country level ethics review boards approved the GSHS, and "informed consent was obtained from the students, parents and/or school officials" [18].

\subsection{Measures}

The questionnaire used was from the GSHS [18] and is shown in Table 1. The psychological distress items (no close friends, loneliness, anxiety, suicidal ideation and suicide attempt) were summed, and grouped into $0=0$ no, $1=1$ single and $2-5=2$ multiple. Underweight was defined "as less than $-2 \mathrm{SD}$ from median for BMI by age and sex", and overweight or obesity was defined as "more than +1 standard deviation (SD) from the median body mass index by age and sex" [19]. Adequate fruit consumption was classified as "two or more servings in a day and adequate consumption of vegetables as three or more servings a day" [20]. Adequate physical activity was defined as "at least $60 \mathrm{~min}$ of 
moderate to vigorous-intensity physical activity daily" [21]. The four items on parental or guardian support were summed, and classified into three groups, 0-1 low, 2 medium and 3-4 high support. Variables for inclusion as covariates were selected based on a previous literature review [2].

Table 1. Variable description.

\begin{tabular}{|c|c|c|}
\hline Variables & Question & Response Options \\
\hline Age & "How old are you?" & "11 years old or younger to 18 years old or older" \\
\hline Sex & "What is your sex?" & "Male, Female" \\
\hline Hunger & $\begin{array}{c}\text { "During the past } 30 \text { days, how often did you go } \\
\text { hungry because there was not enough food in } \\
\text { your home?" }\end{array}$ & $" 1=$ never to $5=$ always $(\operatorname{coded} 1-3=0$ and $4-5=1) "$ \\
\hline Leisure-time sedentary behavior & $\begin{array}{l}\text { "How much time do you spend during a typical } \\
\text { or usual day sitting and watching television, } \\
\text { playing computer games, talking with friends, or } \\
\text { doing other sitting activities, such as ... country } \\
\text { specific examples?" }\end{array}$ & $\begin{array}{c}\text { " } 1=\text { less than } 1 \mathrm{~h} \text { per day } ; 2=1-2 \mathrm{~h} / \text { day } ; 3=3-4 \mathrm{~h} / \text { day } ; 4 \\
=5-6 \mathrm{~h} / \text { day } ; 5=7-8 \mathrm{~h} / \text { day and } 6=8 \text { or more hours per } \\
\text { day" }\end{array}$ \\
\hline Physical activity & $\begin{array}{c}\text { "During the past } 7 \text { days, on how many days were } \\
\text { you physically active for a total of at least } 60 \mathrm{~min} \\
\text { per day? ADD UP ALL THE TIME YOU SPENT } \\
\text { IN ANY KIND OF PHYSICAL ACTIVITY EACH } \\
\text { DAY" }\end{array}$ & $" 1=0$ days to $8=7$ days $(\operatorname{coded} 1-7=0$ and $8=1) "$ \\
\hline Height & "How tall are you without your shoes on?" & $\mathrm{cm}$ \\
\hline Body weight & $\begin{array}{l}\text { "How much do you weigh without your shoes } \\
\text { on?" }\end{array}$ & $\mathrm{kg}$ \\
\hline Fruits & $\begin{array}{c}\text { "During the past } 30 \text { days, how many times per } \\
\text { day did you usually eat fruit such as ... country } \\
\text { specific names?" }\end{array}$ & $\begin{array}{c}\text { " } 1=\mathrm{I} \text { did not eat fruit during the past } 30 \text { days to } 7=5 \text { or } \\
\text { more times per day (coded } 1-3=0 \text { and } 4-8=1) "\end{array}$ \\
\hline Vegetables & $\begin{array}{c}\text { "During the past } 30 \text { days, how many times per } \\
\text { day did you usually eat vegetables, such as ... } \\
\text { country specific names?" }\end{array}$ & $\begin{array}{l}\text { "I did not eat vegetables during the past } 30 \text { days to } 7=5 \\
\text { or more times per day (coded } 1-4=0 \text { and } 5-8=1 \text { " }\end{array}$ \\
\hline Soft drinks & $\begin{array}{l}\text { "During the past } 30 \text { days, how many times per } \\
\text { day did you usually drink carbonated soft drinks, } \\
\text { such as ... country specific names?" }\end{array}$ & $\begin{array}{l}\text { " } 1=\text { not in the past days to } 7=5 \text { or more times per day } \\
\text { (coded } 1=0 \text { and } 2-7=1) "\end{array}$ \\
\hline Fast food & $\begin{array}{l}\text { "During the past seven days, on how many days } \\
\text { did you eat food from a fast food restaurant, such } \\
\text { as ... country specific names?" }\end{array}$ & " $1=0$ to $8=7$ days $(\operatorname{coded} 1-3=0$ and $4-8=1) "$ \\
\hline Bullied & $\begin{array}{l}\text { "During the past } 30 \text { days, on how many days } \\
\text { were you bullied?" }\end{array}$ & $" 1=0$ days to $7=$ All 30 days $(\operatorname{coded} 1=0$ and $2-7=1) "$ \\
\hline Peer support & $\begin{array}{l}\text { "During the past } 30 \text { days, how often were most of } \\
\text { the students in your school kind and helpful?" }\end{array}$ & $" 1=$ never to $5=$ always $($ coded $1-3=0$ and $4-5=1) "$ \\
\hline Parental/guardian supervision & $\begin{array}{c}\text { "During the past } 30 \text { days, how often did your } \\
\text { parents or guardians check to see if your } \\
\text { homework was done?" }\end{array}$ & " $1=$ never to $5=$ always $(\operatorname{coded} 1-3=0$ and $4-5=1)$ " \\
\hline Parental/guardian connectedness & $\begin{array}{c}\text { "During the past } 30 \text { days, how often did your } \\
\text { parents or guardians understand your problems } \\
\text { and worries?" }\end{array}$ & " $1=$ never to $5=$ always $(\operatorname{coded} 1-3=0$ and $4-5=1)$ " \\
\hline Parental/guardian bonding & $\begin{array}{l}\text { "During the past } 30 \text { days, how often did your } \\
\text { parents or guardians really know what you were } \\
\text { doing with your free time?" }\end{array}$ & " $1=$ never to $5=$ always $(\operatorname{coded} 1-3=0$ and $4-5=1)$ " \\
\hline $\begin{array}{l}\text { Parental/guardian respect for } \\
\text { privacy }\end{array}$ & $\begin{array}{c}\text { "During the past } 30 \text { days, how often did your } \\
\text { parents or guardians go through your things } \\
\text { without your approval?" }\end{array}$ & $" 1=$ never to $5=$ always $(\operatorname{coded} 1-3=0$ and $4-5=1) "$ \\
\hline \multicolumn{3}{|c|}{ Psychological distress indicators } \\
\hline No close friends & "How many close friends do you have?" & $" 1=0$ to $4=3$ or more $(\operatorname{coded} 1+=0,0=1) "$ \\
\hline Loneliness & $\begin{array}{l}\text { "During the past } 12 \text { months, how often have you } \\
\text { felt lonely?" }\end{array}$ & $" 1=$ never to $5=$ always $(\operatorname{coded} 1-3=0$ and $4-5=1)$ " \\
\hline Anxiety & $\begin{array}{c}\text { "During the past } 12 \text { months, how often have you } \\
\text { been so worried about something that you could } \\
\text { not sleep at night?" }\end{array}$ & $" 1=$ never to $5=$ always $(\operatorname{coded} 1-3=0$ and $4-5=1) "$ \\
\hline Suicide ideation & $\begin{array}{l}\text { "During the past } 12 \text { months, did you ever } \\
\text { seriously consider attempting suicide?" }\end{array}$ & "Yes, $\mathrm{No}^{\prime}$ \\
\hline Suicide attempt & $\begin{array}{c}\text { "During the past } 12 \text { months, how many times did } \\
\text { you actually attempt suicide?" }\end{array}$ & $\begin{array}{c}\text { "1 }=0 \text { times to } 5=6 \text { or more times }(\operatorname{coded} 1=0 \text { and } 2-5 \\
=1) "\end{array}$ \\
\hline \multicolumn{3}{|c|}{ Substance use } \\
\hline Past month or current tobacco use & $\begin{array}{c}\text { "During the past } 30 \text { days, on how many days did } \\
\text { you smoke cigarettes/use any tobacco products } \\
\text { other than cigarettes, such as such as country } \\
\text { examples ...?" }\end{array}$ & $" 1=0$ days to $7=$ All 30 days $(\operatorname{coded} 1=0$ and $2-7=1)$ " \\
\hline Current alcohol use & $\begin{array}{l}\text { "During the past } 30 \text { days, on how many days did } \\
\text { you have at least one drink containing alcohol?" }\end{array}$ & $" 1=0$ days to $7=$ All 30 days $($ coded $1=0$ and $2-7=1) "$ \\
\hline
\end{tabular}




\subsection{Data Analysis}

Data analysis was conducted with STATA software version 15.0 (Stata Corporation, College Station, TX, USA), taking into account the complex study design. Multinomial logistic regression was used to assess the associations between leisure-time sedentary behavior and single and multiple psychological distress (with no psychological distress as reference category), in Model 1: adjusted for country, and in Model 2: adjusted for country, age, sex, experience of hunger, physical activity, body weight status, fruit and vegetable consumption, soft drink consumption, fast food consumption, bullying victimization, peer support and parental support. Multivariate logistic regression was used to assess the associations of leisure-time sedentary behavior with the prevalence of current tobacco use and current alcohol use, in Model 1: adjusted for country, and in Model 2: adjusted for country, age, sex, experience of hunger, physical activity, body weight status, fruit and vegetable consumption, soft drink consumption, fast food consumption, bullying victimization, peer support and parental support. A $p$-value of $<0.05$ was considered significant.

\section{Results}

\subsection{Sample Characteristics}

The total sample 32,696 school-going adolescents from five Southeast Asian countries, median age 14 years (interquartile range $=2$ years), with complete sedentary behavior measurements from 10,922 students from Indonesia (overall response rate $=94 \%$ ), 3671 from Laos $(72 \%), 8665$ from the Philippines (79\%), 5780 from Thailand $(89 \%)$ and 3658 from Timor-Leste (response rate $=79 \%$ ) [18]. Country participation ranged from Laos and Timor-Leste $11.2 \%$ to Indonesia $33.4 \%$. Overall, the students engaged in $<1 \mathrm{~h}(35.7 \%), 1-2 \mathrm{~h}(31.6 \%), 3-4 \mathrm{~h}(18.2 \%), 5-6 \mathrm{~h}(7.2 \%)$, and 7 or more hours $(7.2 \%)$ of leisure-time sedentary behavior a day. The prevalence of psychological distress was $14.6 \%$ single and $8.6 \%$ multiple psychological distress, and the prevalence of current tobacco use was $13.9 \%$ and current alcohol use $12.5 \%$ (see Table 2). 
Table 2. Sample characteristics by sedentary behavior, psychological distress and substance use.

\begin{tabular}{|c|c|c|c|c|c|c|c|c|c|c|}
\hline \multirow{3}{*}{ Variable } & \multicolumn{6}{|c|}{ Leisure-Time Sedentary Behavior (in hours/day) } & \multicolumn{2}{|c|}{ Psychological Distress } & \multirow{2}{*}{$\begin{array}{l}\text { Tobacco Use } \\
\text { Past Month }\end{array}$} & \multirow{2}{*}{\begin{tabular}{|l} 
Alcohol Use \\
Past Month
\end{tabular}} \\
\hline & Sample & $<1$ & $1-2$ & $3-4$ & $5-6$ & 7 or More & Single & Multiple & & \\
\hline & $N(\%)$ & $\%$ & $\%$ & $\%$ & $\%$ & $\%$ & $\%$ & $\%$ & $\%$ & $\%$ \\
\hline All & 32,696 & 35.7 & 31.6 & 18.2 & 7.2 & 7.2 & 14.6 & 8.6 & 13.9 & 12.5 \\
\hline \multicolumn{11}{|l|}{ Country } \\
\hline Indonesia & $10,922(33.4)$ & 37.1 & 35.6 & 16.8 & 5.4 & 5.2 & 10.9 & 4.5 & 12.8 & 4.4 \\
\hline Laos & 3671 (11.2) & 41.9 & 37.0 & 13.7 & 3.3 & 4.1 & 13.5 & 3.4 & 6.2 & 29.3 \\
\hline Philippines & 8665 (26.5) & 40.8 & 28.0 & 17.2 & 6.7 & 7.3 & 21.0 & 14.5 & 15.8 & 21.2 \\
\hline Thailand & 5780 (17.7) & 19.1 & 24.6 & 26.0 & 15.7 & 14.6 & 14.4 & 12.0 & 13.9 & 22.0 \\
\hline Timor-Leste & $3658(11.2)$ & 50.7 & 34.5 & 7.6 & 2.2 & 4.9 & 23.4 & 11.0 & 30.2 & 17.0 \\
\hline \multicolumn{11}{|l|}{ Age in years } \\
\hline 13 or less & $9420(28.9)$ & 42.1 & 32.8 & 14.9 & 5.1 & 5.2 & 12.8 & 6.3 & 10.0 & 6.7 \\
\hline 14 & $6732(20.7)$ & 34.4 & 33.3 & 17.8 & 7.0 & 7.5 & 14.5 & 8.5 & 13.3 & 10.2 \\
\hline 15 & $6313(19.4)$ & 34.5 & 30.7 & 19.3 & 7.7 & 7.8 & 16.1 & 10.6 & 16.1 & 14.5 \\
\hline 16 or more & $10,102(31.0)$ & 28.2 & 28.9 & 22.9 & 10.5 & 9.6 & 16.1 & 10.7 & 18.7 & 22.0 \\
\hline \multicolumn{11}{|l|}{ Sex } \\
\hline Female & $17,751(54.8)$ & 35.1 & 31.8 & 18.5 & 7.1 & 7.5 & 14.7 & 9.8 & 5.5 & 9.1 \\
\hline Male & $14,662(45.2)$ & 36.4 & 31.5 & 17.8 & 7.4 & 6.9 & 14.5 & 7.4 & 22.7 & 16.0 \\
\hline Hunger (mostly/always) & $1884(5.1)$ & 41.8 & 25.2 & 15.1 & 7.5 & 10.4 & 25.1 & 18.1 & 19.8 & 17.1 \\
\hline \multicolumn{11}{|l|}{ Body weight } \\
\hline Normal & $23,206(77.2)$ & 35.8 & 31.5 & 18.0 & 7.3 & 7.4 & 14.1 & 8.5 & 12.6 & 12.0 \\
\hline Underweight & $2796(8.7)$ & 38.0 & 31.2 & 17.2 & 7.6 & 6.1 & 12.6 & 7.5 & 14.4 & 12.0 \\
\hline Overweight/obese & $3714(14.0)$ & 30.7 & 32.0 & 21.4 & 7.9 & 7.9 & 13.0 & 7.2 & 11.1 & 9.1 \\
\hline Fruit consumption ( $\geq 2 /$ day) & $10,690(36.4)$ & 35.9 & 32.0 & 18.1 & 7.1 & 6.9 & 13.8 & 8.2 & 12.7 & 12.0 \\
\hline Vegetable consumption ( $\geq 3 /$ day) & $8523(28.3)$ & 38.1 & 30.4 & 17.8 & 6.5 & 7.3 & 14.2 & 8.4 & 12.2 & 11.1 \\
\hline Soft drink consumption ( $\geq 2 /$ day) & $5655(15.0)$ & 28.9 & 28.3 & 21.1 & 9.8 & 11.9 & 17.7 & 14.0 & 19.4 & 21.1 \\
\hline Fast food ( $\geq 1 /$ week) & $18,205(56.5)$ & 31.6 & 31.5 & 20.0 & 8.4 & 8.5 & 14.9 & 9.2 & 14.8 & 14.2 \\
\hline Bullied & $11,078(36.8)$ & 35.2 & 30.2 & 18.3 & 7.9 & 8.4 & 21.6 & 16.7 & 21.0 & 19.7 \\
\hline
\end{tabular}


Table 2. Cont.

\begin{tabular}{|c|c|c|c|c|c|c|c|c|c|c|}
\hline \multirow{3}{*}{ Variable } & \multirow[b]{2}{*}{ Sample } & \multicolumn{5}{|c|}{ Leisure-Time Sedentary Behavior (in hours/day) } & \multicolumn{2}{|c|}{ Psychological Distress } & \multirow{2}{*}{$\begin{array}{c}\text { Tobacco Use } \\
\text { Past Month }\end{array}$} & \multirow{2}{*}{$\begin{array}{l}\text { Alcohol Use } \\
\text { Past Month }\end{array}$} \\
\hline & & $<1$ & $1-2$ & $3-4$ & $5-6$ & 7 or More & Single & Multiple & & \\
\hline & $N(\%)$ & $\%$ & $\%$ & $\%$ & $\%$ & $\%$ & $\%$ & $\%$ & $\%$ & $\%$ \\
\hline Peer support (mostly/always) & $11,031(36.9)$ & 33.0 & 32.4 & 18.9 & 7.6 & 8.1 & 12.4 & 7.3 & 10.5 & 10.0 \\
\hline \multicolumn{11}{|l|}{ Parental/guardian support index } \\
\hline 0 & $17,003(51.5)$ & 36.5 & 32.1 & 17.5 & 7.0 & 7.0 & 16.6 & 10.9 & 18.0 & 15.7 \\
\hline 1 & $8423(27.0)$ & 34.1 & 31.8 & 19.8 & 7.5 & 6.8 & 12.9 & 6.4 & 10.4 & 9.9 \\
\hline $2-3$ & $6281(21.5)$ & 36.8 & 31.0 & 17.7 & 7.0 & 7.5 & 11.8 & 5.7 & 7.0 & 6.9 \\
\hline \multicolumn{11}{|l|}{ Psychological distress } \\
\hline single & 4969 (14.6) & 14.4 & 13.0 & 15.7 & 16.2 & 18.1 & & & & \\
\hline multiple & $2802(8.6)$ & 6.9 & 7.4 & 9.7 & 13.3 & 15.4 & & & & \\
\hline Current tobacco use & 4488 (13.9) & 11.9 & 13.8 & 14.6 & 18.4 & 18.0 & & & & \\
\hline Current alcohol use & $4801(12.5)$ & 9.7 & 11.3 & 14.4 & 18.2 & 20.9 & & & & \\
\hline
\end{tabular}




\subsection{Associations between Leisure-Time Sedentary Behaviour and Psychological Distress}

In fully adjusted multinomial logistic regression analysis, compared to students who spent less than one hour a day engaged in leisure-time sedentary behavior, students who spent three or more hours engaged in leisure-time sedentary behavior were more likely to have single and multiple psychological distress (see Table 3).

Table 3. Associations of leisure-time sedentary behavior with single and multiple psychological distress (with no psychological distress as reference category).

\begin{tabular}{|c|c|c|}
\hline Variable & Single Psychological Distress & Multiple Psychological Distress \\
\hline & ARRR $^{1}$ & $\mathrm{ARRR}^{1}$ \\
\hline \multicolumn{3}{|c|}{$\begin{array}{l}\text { Leisure-time sedentary behavior, } \\
\text { hours/day }\end{array}$} \\
\hline$<1$ & 1 (Reference) & 1 (Reference) \\
\hline $1-2$ & $0.95(0.85,1.07)$ & $1.16(0.99,1.37)$ \\
\hline $3-4$ & $1.18(1.04,1.35)^{*}$ & $1.46(1.25,1.71)^{* * *}$ \\
\hline $5-6$ & $1.26(1.05,1.35) *$ & $1.99(1.63,2.44)^{* * *}$ \\
\hline \multirow[t]{2}{*}{7 or more } & $1.49(1.22,1.81)^{* * *}$ & $2.42(1.99,2.96)^{* * *}$ \\
\hline & ARRR $^{2}$ & $\mathrm{ARRR}^{2}$ \\
\hline \multicolumn{3}{|c|}{$\begin{array}{l}\text { Leisure-time sedentary behavior, } \\
\text { hours/day }\end{array}$} \\
\hline$<1$ & 1 (Reference) & 1 (Reference) \\
\hline $1-2$ & $0.92(0.81,1.05)$ & $1.17(0.96,1.44)$ \\
\hline $3-4$ & $1.18(1.02,1.36)^{*}$ & $1.50(1.23,1.83)^{* * *}$ \\
\hline $5-6$ & $1.29(1.04,1.60) *$ & $2.06(1.56,2.71) * * *$ \\
\hline 7 or more & $1.49(1.19,1.88)^{* * *}$ & $2.39(1.86,3.09) * * *$ \\
\hline
\end{tabular}

\subsection{Associations of Leisure-Time Sedentary Behaviour with Tobacco and Alcohol Use}

In fully adjusted logistic regression analysis, five or more hours of leisure-time sedentary behavior was associated with current tobacco use, and 1-2 h or more of sedentary time was associated with current alcohol use (see Table 4).

Table 4. Associations between leisure-time sedentary behavior and tobacco and alcohol use.

\begin{tabular}{ccc}
\hline Variable & \multicolumn{2}{c}{ Current Tobacco Use } \\
\hline \multicolumn{1}{c}{ AOR $^{1}$} & AOR $^{2}$ \\
\hline $\begin{array}{c}\text { Leisure-time sedentary behavior, } \\
\text { hours/day }\end{array}$ & & \\
$<1$ & 1 (Reference) & 1 (Reference) \\
$1-2$ & $1.21(1.03,1.43)^{* *}$ & $1.10(0.93,1.29)$ \\
$3-4$ & $1.30(1.10,1.53)^{* *}$ & $1.10(0.90,1.34)$ \\
$5-6$ & $1.71(1.41,2.08)^{* * *}$ & $1.55(1.22,1.98)^{* * *}$ \\
7 or more & $1.66(1.32,2.07)^{* * *}$ & $1.55(1.14,2.11)^{* *}$ \\
\hline & AOR $^{1}$ & AOR $^{2}$ \\
\hline Leisure-time sedentary behavior, & & \\
hours/day & & $1($ Reference) \\
$<1$ & $1($ Reference) & $1.18(1.03,1.35)^{*}$ \\
$1-2$ & $1.32(1,14,1,52)^{* * *}$ & $1.31(1.12,1.52)^{* * *}$ \\
$3-4$ & $1.50(1.31,1.72)^{* * *}$ & $1.52(1.25,1.85)^{* * *}$ \\
$5-6$ & $1.76(1.50,2.07)^{* * *}$ & $1.87(1.61,2.18)^{* * *}$ \\
\hline 7 or more & $2.06(1.77,2.41)^{* * *}$ &
\end{tabular}

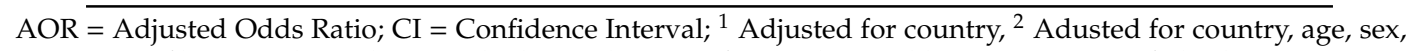
experience of hunger, physical activity, body weight status, fruit and vegetable consumption, soft drink consumption, fast food consumption, bullying victimization, peer support and parental support. ${ }^{* * *} p<0.001,{ }^{* *} p<0.01,{ }^{*} p<0.05$. 


\section{Discussion}

This study aimed to estimate associations of leisure-time sedentary behavior with psychological distress and with substance use among adolescents in Southeast Asia. Consistent with a previous review and multi-country studies among adolescents [2,9-12], this study found that higher leisure-time sedentary behavior ( $\geq 3 \mathrm{~h}$ ) increased the risk ratio for psychological distress, after adjusting for relevant confounders, in this population of school-going adolescents. Further, this study found that compared to $<1 \mathrm{~h}$ leisure-time sedentary behavior, students with five or more hours leisure time sedentary behavior had a higher odds of current tobacco use and students with one or more hours leisure-time sedentary behavior had a higher odds of current alcohol use. This finding is in agreement with studies in USA and Africa [14,16].

The association between leisure-time sedentary behavior and psychological distress was stronger in students with multiple psychological distress (Adjusted Relative Risk Ratio (ARRR): 2.39, Confidence Interval (CI): 1.86, 3.09), compared to students with single psychological distress (ARRR: 1.49, CI: 1.19, 1.88). This study also found a dose-dependent association between leisure-time sedentary behavior and having multiple psychological distress, current tobacco and alcohol use, as found previously with poor mental health outcomes [7,8]. The prevalence of multiple psychological distress increased from $6.9 \%$ with $<1 \mathrm{~h}$ leisure-time sedentary behavior per day to $15.4 \%$ with seven or more hours leisure-time sedentary behavior per day. Similarly, current tobacco use increased from $11.9 \%$ to $18.0 \%$ and current alcohol use increased from $9.7 \%$ with $<1 \mathrm{~h}$ leisure-time sedentary behavior per day to $20.9 \%$ with seven or more hours leisure-time sedentary behavior per day. Some experimental research seems to suggest a causal relationship from sedentary behavior to psychological distress [22]. Moreover, adolescents who have psychological distress may be more likely to develop more sedentary behavior [2,7]. In addition, increased social media use may be by itself linked to increased psychological distress $[8,23,24]$.

The association between sedentary behavior and substance use was stronger for alcohol than for tobacco use. Chiao et al. [25] found in a longitudinal study that adolescent internet use was associated with alcohol use and cigarette smoking. It is possible that increased and possibly problematic social media use as a behavioral addiction develops in co-occurrence with substance use (tobacco and alcohol) addiction $[14,26]$.

\section{Study Limitations}

Based on the cross-sectional nature of this study, no causal conclusions can be drawn. Further, the leisure-time sedentary behavior and other variables were assessed by a self-reported questionnaire. Future studies should include both self-reported and objective measures of sedentary behavior. Another limitation was that screen time was only assessed together with overall leisure-time sedentary behavior, and we cannot therefore discern effects of screen time and other sedentary behavior.

\section{Conclusions}

Our findings confirm previous results demonstrating an association between leisure-time sedentary behavior and psychological distress. In addition, findings from a few previous studies are extended by showing associations of higher leisure-time sedentary behavior with tobacco and alcohol use. Mental health and substance use intervention strategies among school-going adolescents may include reducing and/or interrupting sedentary behavior.

Author Contributions: S.P. and K.P. designed the analysis, analyzed the data, wrote the manuscript, and approved the paper.

Funding: This research received no external funding.

Acknowledgments: The World Health Organization is acknowledged for making the datasets publicly available for this analysis.

Conflicts of Interest: The authors declare no conflict of interest. 


\section{References}

1. Kessler, R.C.; Amminger, G.P.; Aguilar-Gaxiola, S.; Alonso, J.; Lee, S.; Ustün, T.B. Age of onset of mental disorders: A review of recent literature. Curr. Opin. Psychiatry 2007, 20, 359-364. [CrossRef] [PubMed]

2. Hoare, E.; Milton, K.; Foster, C.; Allender, S. The associations between sedentary behaviour and mental health among adolescents: A systematic review. Int. J. Behav. Nutr. Phys. Act. 2016, 13, 108. [CrossRef] [PubMed]

3. Biddle, S.J.; Gorely, T.; Stensel, D.J. Health-enhancing physical activity and sedentary behaviour in children and adolescents. J. Sports Sci. 2004, 22, 679-701. [CrossRef] [PubMed]

4. Panahi, S.; Tremblay, A. Sedentariness and health: Is sedentary behavior more than just physical inactivity? Front. Pub. Health 2018, 6, 258. [CrossRef] [PubMed]

5. Biddle, S.J.; García Bengoechea, E.; Wiesner, G. Sedentary behaviour and adiposity in youth: A systematic review of reviews and analysis of causality. Int. J. Behav. Nutr. Phys. Act. 2017, 14, 43. [CrossRef] [PubMed]

6. De Rezende, L.F.; Rodrigues Lopes, M.; Rey-López, J.P.; Matsudo, V.K.; Luiz Odo, C. Sedentary behavior and health outcomes: An overview of systematic reviews. PLoS ONE 2014, 9, 105620. [CrossRef]

7. Mitter, S. Globalization, technological changes and the search for a new paradigm for women's work. Gend. Technol. Dev. 1999, 3, 3-17.

8. Kelly, Y.; Zilanawala, A.; Booker, C.; Sacker, A. Social media use and adolescent mental health: Findings from the UK Millennium Cohort Study. EClinicalMedicine 2018, 6, 59-68. [CrossRef]

9. Vancampfort, D.; Stubbs, B.; Firth, J.; Van Damme, T.; Koyanagi, A. Sedentary behavior and depressive symptoms among 67,077 adolescents aged 12-15 years from 30 low- and middle-income countries. Int. J. Behav. Nutr. Phys. Act. 2018, 15, 73. [CrossRef]

10. Vancampfort, D.; Ashdown-Franks, G.; Smith, L.; Firth, J.; Van Damme, T.; Christiaansen, L.; Stubbs, B.; Koyanagi, A. Leisure-time sedentary behavior and loneliness among 148,045 adolescents aged 12-15 years from 52 low- and middle-income countries. J. Affect. Disord. 2019, 251, 149-155. [CrossRef]

11. Vancampfort, D.; Stubbs, B.; Mugisha, J.; Firth, J.; Van Damme, T.; Smith, L.; Koyanagi, A. Leisure-time sedentary behavior and suicide attempt among 126,392 adolescents in 43 countries. J. Affect. Disord. 2019, 250, 346-353. [CrossRef]

12. Vancampfort, D.; Van Damme, T.; Stubbs, B.; Smith, L.; Firth, J.; Hallgren, M.; Mugisha, J.; Koyanagi, A. Sedentary behavior and anxiety-induced sleep disturbance among 181,093 adolescents from 67 countries: A global perspective. Sleep Med. 2019, 58, 19-26. [CrossRef] [PubMed]

13. Rodriguez-Ayllon, M.; Cadenas-Sánchez, C.; Estévez-López, F.; Muñoz, N.E.; Mora-Gonzalez, J.; Migueles, J.H.; Molina-García, P.; Henriksson, H.; Mena-Molina, A.; Martínez-Vizcaíno, V.; et al. Role of physical activity and sedentary behavior in the mental health of preschoolers, children and adolescents: A systematic review and meta-analysis. Sports Med. 2019. [CrossRef] [PubMed]

14. Lesjak, V.; Stanojević-Jerković, O. Physical activity, sedentary behavior and substance use among adolescents in Slovenian urban area. Zdr. Varst. 2015, 54, 168-174. [CrossRef] [PubMed]

15. Lebron, C.; Stoutenberg, M.; Janowsky, M.; Asfour, L.; Huang, S.; Prado, G. The role of physical activity and sedentary behavior in substance use and risky sex behaviors in Hispanic adolescents. J. Early Adolesc. 2017, 37, 910-924. [CrossRef]

16. Peltzer, K. Leisure time physical activity and sedentary behavior and substance use among in-school adolescents in eight African countries. Int. J. Behav. Med. 2010, 17, 271-278. [CrossRef]

17. Peltzer, K.; Pengpid, S. Leisure Time Physical Inactivity and Sedentary Behaviour and Lifestyle Correlates among Students Aged 13-15 in the Association of Southeast Asian Nations (ASEAN) Member States, 2007-2013. Int. J. Env. Res. Public Health 2016, 13, 217. [CrossRef]

18. World Health Organization (WHO). Global School-Based Student Health Survey (GSHS). 2019. Available online: https://www.who.int/ncds/surveillance/gshs/en/ (accessed on 2 March 2019).

19. Cole, T.J.; Bellizzi, M.C.; Flegal, K.M.; Dietz, W.H. Establishing a standard definition for child overweight and obesity worldwide: International survey. BMJ 2000, 320, 1240-1243. [CrossRef]

20. Centers for Disease Control and Prevention (CDC). State Indicator Report on Fruits and Vegetables. 2013. Available online: http://www.cdc.gov/nutrition/downloads/state-indicator-reportfruits-vegetables-2013.pdf (accessed on 10 December 2017). 
21. World Health Organization. Physical Activity Fact Sheet. 2017. Available online: http://www.who.int/ mediacentre/factsheets/fs385/en/ (accessed on 10 April 2019).

22. Edwards, M.K.; Loprinzi, P.D. Experimentally increasing sedentary behavior results in increased anxiety in an active young adult population. J. Affect. Disord. 2016, 204, 166-173. [CrossRef]

23. Sampasa-Kanyinga, H.; Lewis, R.F. Frequent use of social networking sites is associated with poor psychological functioning among children and adolescents. Cyberpsychol. Behav. Soc. Netw. 2015, 18, 380-385. [CrossRef]

24. Aalbers, G.; McNally, R.J.; Heeren, A.; de Wit, S.; Fried, E.I. Social media and depression symptoms: A network perspective. J. Exp. Psychol. Gen. 2018. [CrossRef] [PubMed]

25. Chiao, C.; Yi, C.C.; Ksobiech, K. Adolescent internet use and its relationship to cigarette smoking and alcohol use: A prospective cohort study. Addict. Behav. 2014, 39, 7-12. [CrossRef] [PubMed]

26. Van Rooij, A.J.; Kuss, D.J.; Griffiths, M.D.; Shorter, G.W.; Schoenmakers, M.T.; Van De Mheen, D. The co-occurrence of problematic video gaming, substance use, and psychosocial problems in adolescents. J. Behav. Addict. 2014, 3, 157-165. [CrossRef] [PubMed]

(C) 2019 by the authors. Licensee MDPI, Basel, Switzerland. This article is an open access article distributed under the terms and conditions of the Creative Commons Attribution (CC BY) license (http://creativecommons.org/licenses/by/4.0/). 